\title{
Determination of ground model for capacity increase project for disposal pond of dredged marine deposit
}

\author{
Masato Nakamichii), Shuji Yamamoto ${ }^{\text {ii)}}$, Masaaki Katagiri ${ }^{\text {iii) }}$ and Kanta Ohishi ${ }^{\text {iii) }}$
}

i) Director-General, Kita-Kyushu Port and Airport Office, KRCB, MLIT, 1-4-40, Nishi-kaigan Moji-ku, Kitakyushu 801-0841, Japan. ii) Executive Director, Coastal Development Institute of Technology, 1-14-2, Nishi-shimbashi Minato-ku, Tokyo 105-0003, Japan. iii) Senior Geotechnical Engineer, Nikken Sekkei Civil Engineering, 1-4-27, Koraku Bunkyo-ku, Tokyo 112-0004, Japan.

\begin{abstract}
The ground surface of reclaimed land with dredged clay settles due to self-weight consolidation for a long term. If the ground surface settles rapidly, the settled space can receive additional dredged clays. In this paper, the ground improvement project using vertical drains for such a disposal pond is introduced. The determination of ground model using the reclamation analysis is a key point because the ground condition at the installation of vertical drains is not different from that at the design of ground improvement. The adequacy of proposed method is confirmed to compare with the ground model and pore water pressure distributions measured at the installation of vertical drains.
\end{abstract}

Keywords: vertical drain, dredged clay, prediction, monitoring, excess pore pressure

\section{INTRODUCTION}

The dredging work is required for extending and deepening of sea route and anchorage area. To protect the marine environmental condition, the dredged sea bottom materials are generally discharged into the disposal pond surrounded by the dykes in the sea.

Now, the S-3 area of Shin-Mojioki disposal pond in Fukuoka prefecture in Japan is receiving the dredged clay of Kanmon Waterway and near sea routes (see Fig.1). The original design capacity of disposal pond was insufficient until opening of a new disposal pond. To increase in the capacity of disposal pond, an extra-fill near the shore protection in the S-3 area was constructed. In this case, however, the increment of capacity was not enough against the planned dredged volume up to the open of new disposal pond. Then, the ground improvement using vertical drains (VD's) has been performed as an additional method for increment of capacity of disposal pond. In this method, excess pore water pressure in the reclaimed clay layer disappears through the VD's, and the ground surface settles quickly.

In this paper, the design of VD's for increment of capacity of disposal pond and monitoring results for seven months from the installation of VD's are described.

\section{HISTORY OF S-3 AREA AS DISPOSAL POND}

Figure 2 shows a plan view of the S-3 area of Shin-Mojioki disposal pond. Two dredged areas (South

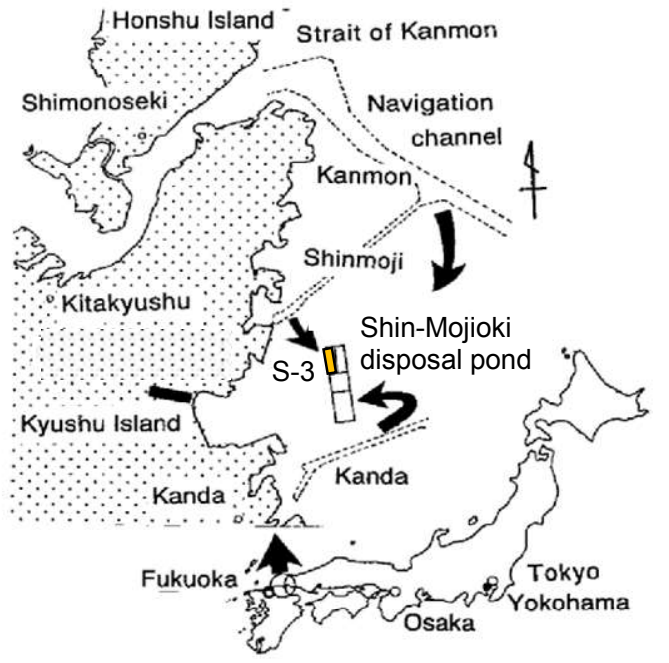

Fig. 1. Site of Shin-Mojioki disposal pond.

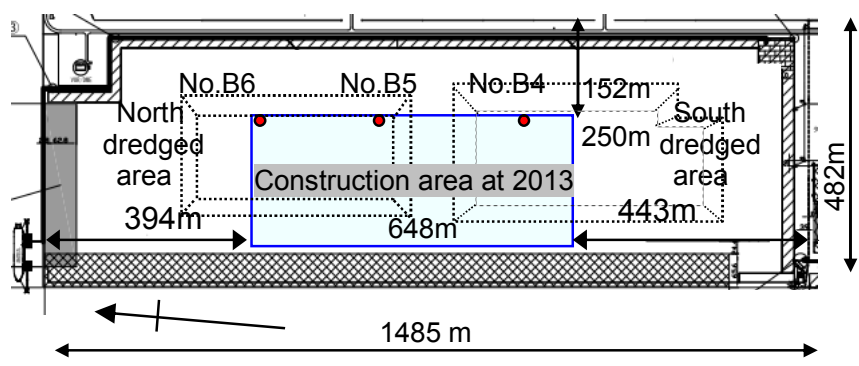

Fig. 2. Improvement area in S-3 area.

and North) in this pond was excavated from DL $-7 \mathrm{~m}$ to about DL $-22 \mathrm{~m}$ before receiving of dredged clays, and these dredged soils were used as reclamation materials for Kita-Kyushu Airport. In the same figure, the points of soil survey performed at 2011 (No.B4 B6), and the 
area of ground improvement held at 2013.

The S-3 area of Shin-Mojioki disposal pond was received dredged clays from 1998, and the elevation of reclaimed ground was approximately $\mathrm{DL}+6.3 \mathrm{~m}$ at the installation of VD's (2013.4). The dredging of marine clays was performed using the drag-suction ship, and the dredged materials were discharged into the pond by barge ships before 2003 and by pipe lines after that.

\section{PROJECT OF CAPACITY INCREMENT OF DISPOSAL POND BY VD METHOD}

\subsection{Sedimentation of dredged clay and back analysis}

Figure 3 shows the vertical distributions of water content and consolidation yield stress of reclaimed clay ground measured at 2011. The water content of surface layer was approximately $120 \%$, the water content in the reclaimed ground decreased as the elevation lowered, and the value at DL-20 m was about $70 \%$. The consolidation yield stresses from ground surface to DL-15 m were less than $7 \mathrm{kPa}$, the consolidation yield stress below DL-15 m increased, and the value around DL-22 $\mathrm{m}$ was approximately $80 \mathrm{kPa}$. In the same figure, overburden stress distribution calculated using wet density of No.B6 was also drawn. Compared between consolidation yield stress and overburden stress, the reclaimed clay ground was recognized to be partially consolidated condition.
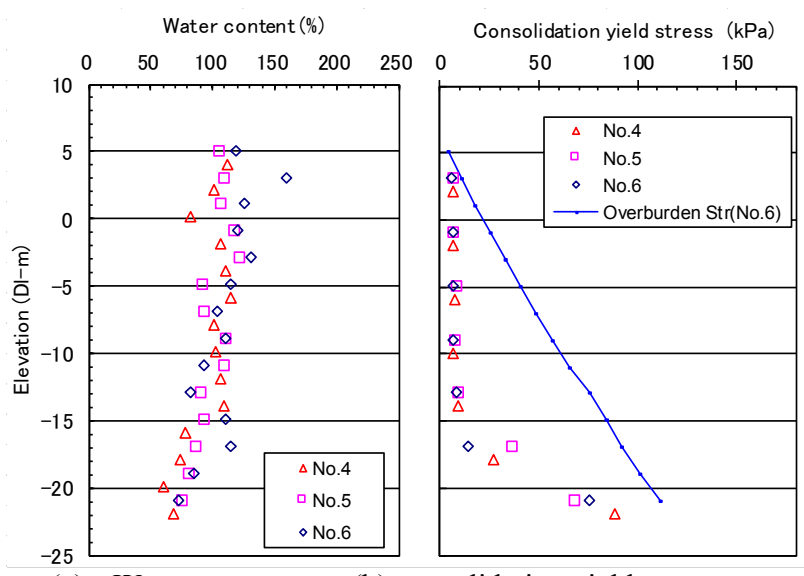

$\begin{array}{ll}\text { (a) Water content } & \text { (b) consolidation yield stress }\end{array}$

Fig.3. Condition of reclaimed layer measured at 2011.
Figure 4(a) shows the comparisons of measured elevations and back analysis result for the discharging process of dredged clays at the north dredged area. In the back analysis, the reclamation analysis according to the history of discharging was performed using the reclamation program named CONAN (Katagiri, et al., 2001). The consolidation parameters for reclamation analysis were modified to express both the time-elevation relation and water content distribution, as shown in Fig.4 (a) and (b). Here, the CONAN was developed from the coupling method proposed by Imai (1995). Fig. 4(b) shows the water content distribution of reclaimed ground at 2011. The result of back analysis shown as a solid curve is drawn around the maximum limit of distribution range.

From these two results, the combination of consolidation parameters $\left(f-p\right.$ and $C_{\mathrm{v}}-p$ relations) was determined as identified parameters.

\subsection{Assessment of consolidation parameters}

Figure 5 shows the relations between consolidation stress and coefficient of consolidation, and between consolidation stress and specific volume, $f(=1+$ void ratio) obtained from the soil survey at 2011. In the same figures, the identified relations used the back analysis shown in Fig. 4 were drawn. The identified relations are located in the middle of range of tested data, and are recognized to be suitable for the back analysis.

\subsection{Design of vertical drain}

As the dredged marine clays will be continuously discharged into the disposal pond, the elevation of ground surface at the installation of VD's (2013.4) will be different from that at the design (2012.8). Therefore, it is necessary to predict the elevation of ground surface and ground condition.

In this project, the elevation of ground and ground condition at the installation of plastic board drain (PBD) were determined from the results of reclamation analysis. The flow of assumption of ground model was as follows; i) Performing the back analysis of reclamation up to the time of design, ii) determining the identified parameters, iii) predicting the performance of reclamation using CONAN and identified parameters, and iv) assuming the ground model from the ground
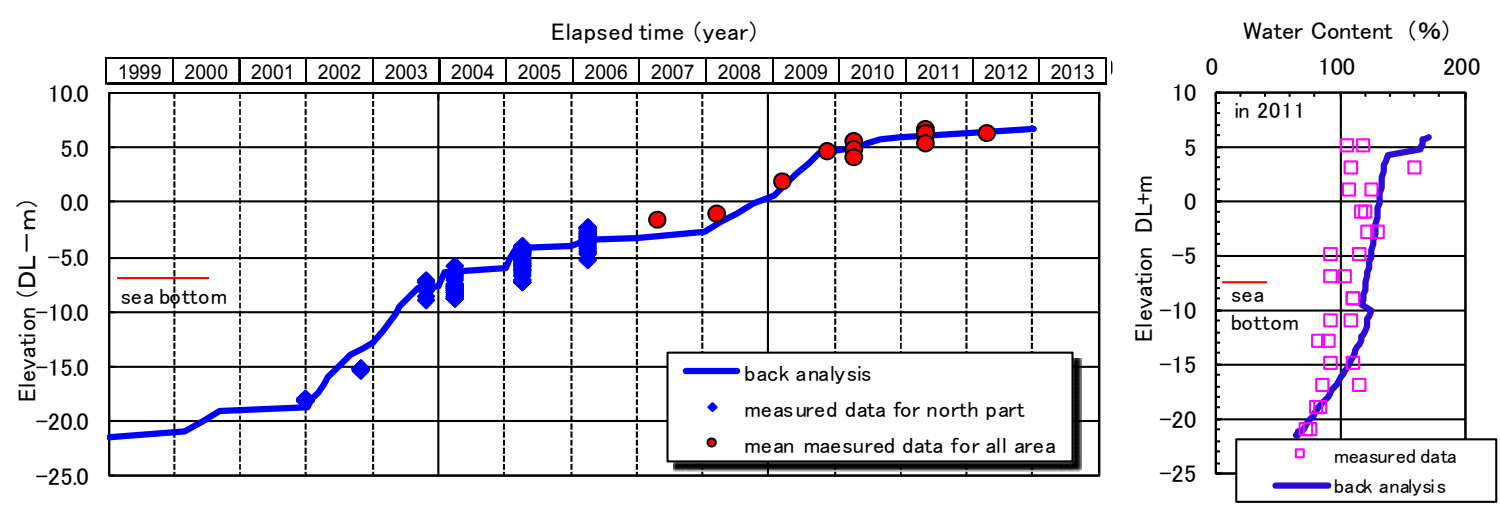

(a) Time-elevation of reclaimed land

(b) Water content distribution

Fig.4. Comparison between measured data and result of back analysis. 
condition calculated from the prediction.

In the design of VD using PBD, the $C_{\mathrm{c}}$-method and Barron's equation were used, and the relationship between installation space of PBD, $d$ and ratio of horizontal and vertical consolidation coefficients of consolidation, $C_{\mathrm{h}} / C_{\mathrm{v}}$ was used as $C_{\mathrm{h}} / C_{\mathrm{v}}=0.77 * d-0.24$ $(0.8<d<3.0)$ obtained from the construction project of New Kitakyushu Airport (Yoshida, et al., 2007).

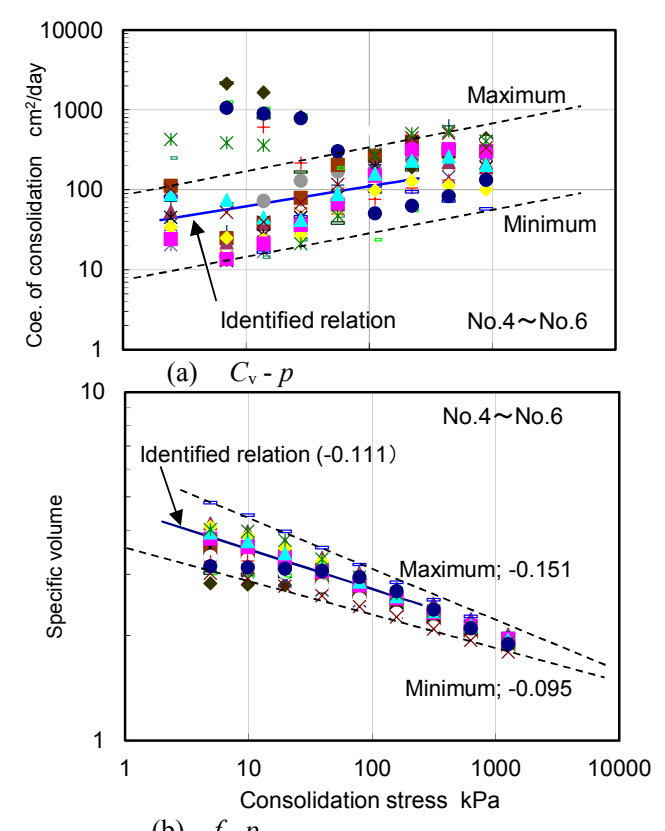

Fig. 5. Consolidation characteristics of dredged clay.

Figure 6 shows the calculated ground condition (water content and effective stress) at the installation of PBD (2013.4). Although the disconnection of water content and elevation curve means the boundary of two layers with different compressibility, the distribution of effective stress shows a smooth curve. From the results of this calculation, the elevation of DL+6.3 m was determined, and the ground model was assumed.

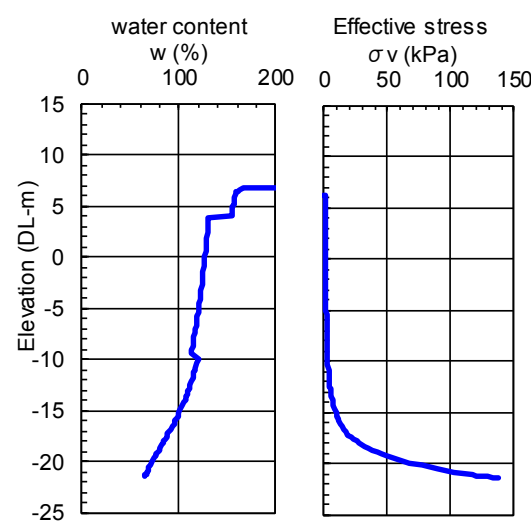

Fig. 6. Calculated results of ground condition.

\section{EVALUATION OF SETTLEMENT AFTER INSTALLATION OF VERTICAL DRAINS}

\subsection{Outline of project}

Before the installation of PBD, the mean elevation of ground for the construction area of 2013 shown in Fig. 2 was measured at $\mathrm{DL}+6.35 \mathrm{~m}$, and was recognized to be almost the same as the prediction at the design. The pitch of installation of PBD was determined as $1.6 \mathrm{~m}$ from the consolidation analysis using Barron's equation and $C_{\mathrm{c}}$-value. The wide PBD with $120 \mathrm{~mm}$ in width instead of sand mat was used as horizontal drainage. To ensure the drainage from VD's, the connection between VD's and horizontal drain was used the mechanical suture.

To measure the settlement of ground after the installation of PBD, 21 of settlement plates were set. For the measurement of change of ground condition, the pore-water pressure transducers (PPT) were set at 3 depths and 4 positions. And the three PPT's were set in PBD to measure the water pressures in VD's with different elevations. The positions of these plates and PPT's are shown in Fig.7.

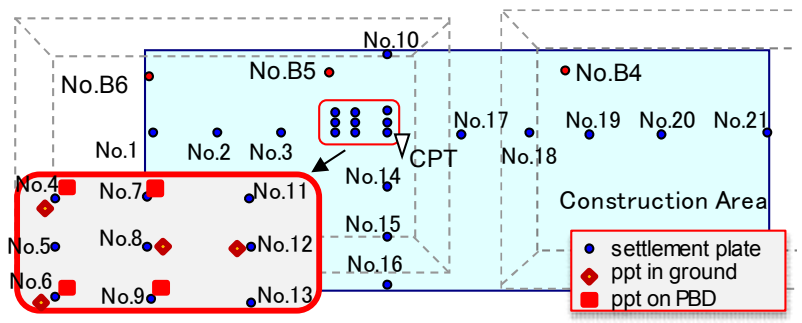

Fig.7. Position of settlement plates and PPT's set.

\subsection{Condition of reclaimed ground just after installation}

Figure 8 shows the distributions of pore-water pressure measured in the ground just after the installation of PBD and calculated by CONAN. The static water pressure at DL $+6.3 \mathrm{~m}$ is also drawn in the same figure. The drainage condition of reclamation analysis was assumed at both the top and bottom of reclaimed ground. The calculated pore-water pressure at DL-22 $\mathrm{m}$ was therefore piled up the static water pressure.

The pore water pressures measured in PBD were almost piled up the static water pressure. The values measured in the ground were larger than the static water pressure, and were consistent with the pore water pressure distribution calculated by reclamation analysis.

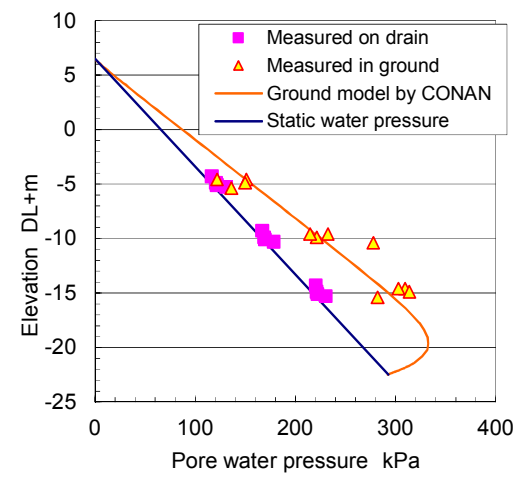

Fig. 8. Measured and calculated pore water pressure distributions. 


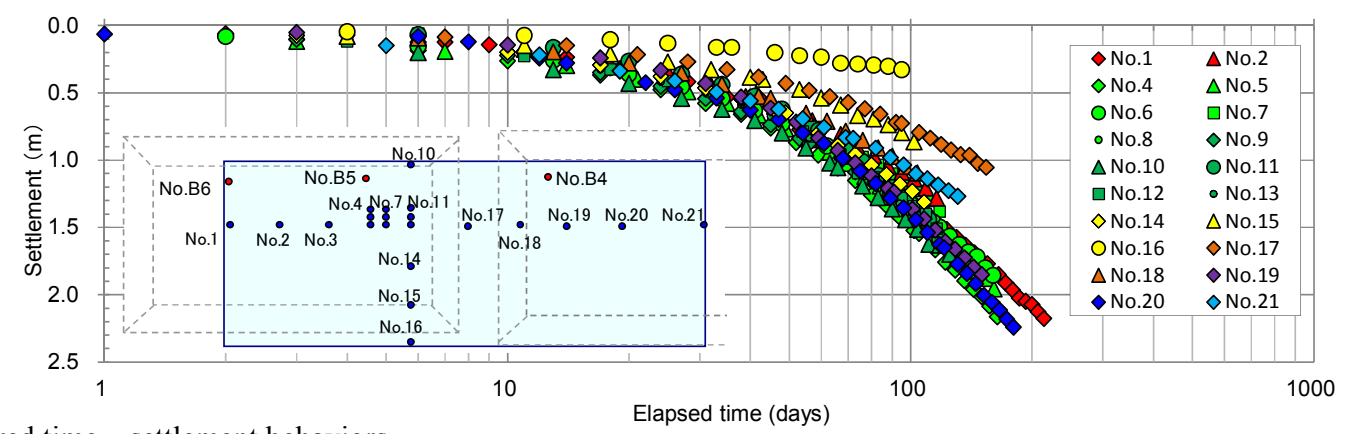

Fig. 9. Measured time - settlement behaviors.

This agreement between measured and calculated pore water pressure distributions means that the proposed determination method of ground model is useful to the design for reclaiming ground.

\subsection{Evaluation of prediction in comparison with monitored settlements}

Figure 9 shows the time-settlement relations monitored up to 2014.3. Because a settlement plate was placed after the installation of PBDs at the area, the measurement term of each settlement plate was different. At No.1, the settlement of about $2.2 \mathrm{~m}$ was generated for 7 months. The position of No.16 was located near the west revetment, and the reclaimed layer was about $15 \mathrm{~m}$ in thickness and was composed of grab dredged sandy clay with low water content. Therefore, the settlement of ground for three months after the installation of PBD's was approximately $0.3 \mathrm{~m}$. At No.17 where was away from the deep dredged areas and was piled on pump-dredged clays, the settlement was approximately $1 \mathrm{~m}$. Depend on the characteristics of dredged clay and the thickness of reclaimed layer, the settlement behaviors were largely different.

Figure 10 shows the measured data at the north dredged area (No.1-14). The solid curve shows the result of Barron's equation for the ground model having excess pore water pressure distribution shown in Fig. 8 with the consolidation constants determined by extrapolation (Yoshida, et al., 2007) of identified consolidation parameters in reclamation analysis shown in Fig. $5\left(C_{\mathrm{c}}=0.95, C_{\mathrm{v}}=80 \mathrm{~cm}^{2} /\right.$ day $)$.

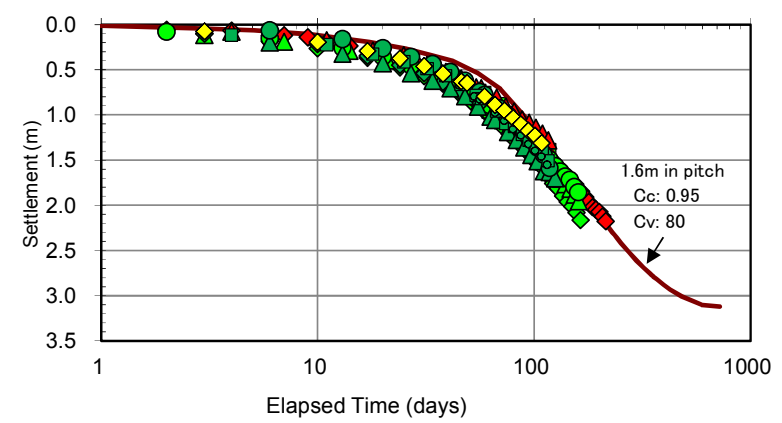

Fig.10. Comparison between measured and calculated settlement behaviors.

Up to 210 days, the calculated time - settlement relation was represented the measured relations. This fact was assessed that the assumption of ground model and consolidation parameters were suitable.

\section{CONCLUDING REMARKS}

In this paper, the ground improvement using VD's for the capacity increase of disposal pond of dredged clays are introduced. Because the settlement of ground surface generates due to disappearance of excess pore water pressure in this case, it is important to predict exactly the excess pore water pressure distribution in the reclaimed ground at the installation of VD's.

Due to continuous discharging of dredged clays, the elevation and condition of reclaimed ground at the installation of VD's would differ from those at the design. The ground model for design of VD's was determined from the result of reclamation analysis. The adequacy of this method was confirmed to compare with the pore water distributions calculated and measured at the installation of VD's, and with settlement behaviors calculated and measured after the installation of VD's.

At the design of ground improvement, the receivable volume at 2011 was predicted about 5.8 million $\mathrm{m}^{3}$. The calculated value was equivalent to about 4.7 million $\mathrm{m}^{3}$ of additional volume from the original volume. Here, the condition of calculation was that the ground improvement with construction area of $334,800 \mathrm{~m}^{2}$ would be performed from 2013 to 2015 .

\section{ACKNOWLEDGEMENTS}

The authors would like to thank the technical committee (Chairperson: Prof. K. Zen of Kyushu University) for their valuable advices.

\section{REFERENCES}

1) Imai, G., (1995): Analytical examinations of the foundations to formulate consolidation phenomena with inherent time-dependence, Proceedings of IS-Hiroshima '95, Vol. 2, 891-935.

2) Katagiri, M., Terashi, M. and Kaneko, A. (2001): Back analysis of reclamation by pump-dredged marine clay -Influence of ground water lowering-, Soils and Foundations, 41(5), 73-86.

3) Yoshida, H., Katagiri, M. and Terashi, M. (2007): Use of dredged clay from navigation channel for airport construction, Proceedings of the 13th Asian Regional Conference on Soil Mechanics and Geotechnical Engineering, 423-426. 